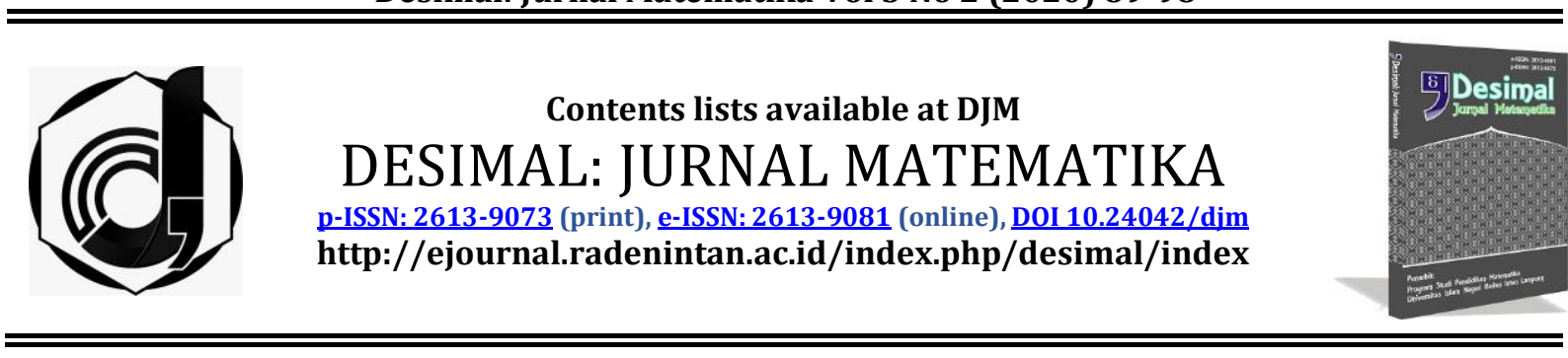

\title{
Questions Analysis in Mathematics Textbook from Competency-Based Curriculum up to Curriculum 2013
}

\author{
Aji Raditya ${ }^{1}$, Ratu Sarah Fauziah Iskandar ${ }^{1}$, Suwarno $^{2}$ \\ ${ }^{1}$ Universitas Muhammadiyah Tangerang, Indonesia \\ 2 Bina Nusantara University, Indonesia
}

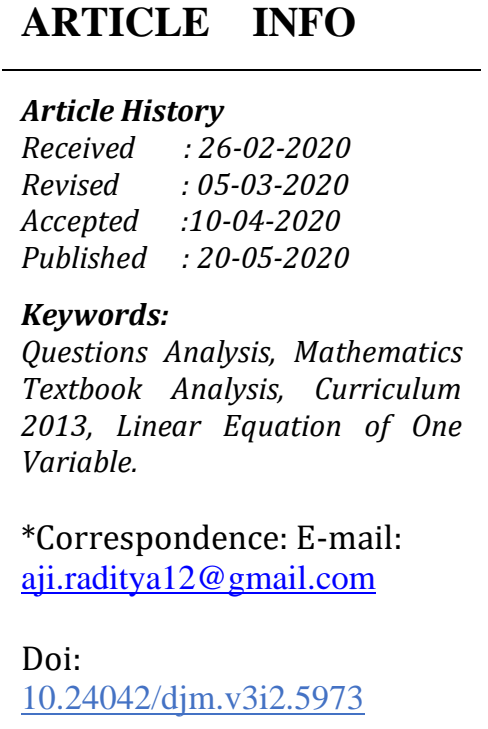

\begin{abstract}
Mathematics textbooks have a significant role in mathematics teaching, and learning activities in schools and the questions contained in textbooks are usually used by students to practice independently. The purpose of this study is to analyze the types of problems in mathematics textbooks used from 2000 to 2017 in Indonesia, especially in the material of one-variable linear equations. The method used in this study is a six-dimensional analysis method, which consists of mathematical activities, the level of difficulty of the questions, the types of answers expected, contextual situations, the types of responses and the types of mathematical questions. Data collection techniques are done by analyzing and describing the types of questions in mathematics textbooks used from 2000 to 2017. The results of this study are the problems in mathematics textbooks for linear variable equations of one variable that do not have diverse types, the types of questions in textbooks are still many in the form of questions that calculate or use a variety of arithmetic operations, apply directly the basic knowledge or skills and without context in everyday life. Also, the existing questions are questions with closed answers, namely questions that only require answers without a reason and questions with a single procedure.
\end{abstract}

http://ejournal.radenintan.ac.id/index.php/desimal/index

\section{INTRODUCTION}

Textbooks have an essential role in mathematics education. Textbooks are one of the written sources that are widely used by teachers and students in conducting learning activities in mathematics in the world or it can be said that textbooks are the primary source in connecting between the existing curriculum with the implementation of learning activities in the classroom and forming learning activities in the class (Glasnovic Gracin, 2018; Özgeldi \& Esen, 2010). One crucial element of a textbook is 
the evaluation element contained in it, for example in the form of questions (both sample questions and practice questions).

In learning activities using textbooks in class, questions are the centre of activities and activities in the classroom (Niss, 1993). Questions are often designed to reveal facts that are known (or unknown) by students, as well as techniques that are mastered (or not mastered) by students and how to use them in certain situations (Brändström, 2005). Watson note that questions must involve more than just practising the algorithms being taught as well as effective problems that should provide opportunities for students to question their reasoning activities and struggle with mathematical ideas (Watson \& Geest, 2005).

This research focuses on analyzing mathematical problems in mathematics textbooks for one-variable linear equation material; usually this material is studied in class VII in junior high school. The important one-variable linear equation topic is this topic can be an indicator for student's algebraic proficiency in school (Huntley \& Terrell, 2014). The mathematical problem will be analyzed with a 6-dimensional framework that is modified from the framework developed by Gracin (2018) and Li (2000), namely mathematical activity (activity), the level of complexity of the problem (complexity level), the type of answer expected (answer form), the type of response (response type), contextual situations (contextual features) and types of mathematical questions (mathematical features).

Love and Pimm (Love \& Pimm, 1996) claim that "exposition - examples of practice questions" are the most common methods used in mathematics textbooks. Exposition refers to the parts where the writer presents the subject matter. Then, the example questions offer students a model to implement, for example, in the next exercise. Meanwhile, the Practice Questions refer to various tasks that students must do. Both example problems and math problem exercises give students the opportunity to think conceptually, perform procedures and encourage connection (Özgeldi \& Esen, 2010). So it can be said that the sample questions and practice questions are an essential part of mathematics textbooks and activities in the mathematics class.

Several studies have been conducted to look at and analyze the types of problems used in mathematics textbooks in various countries. Zhu and Fan (Zhu \& Fan, 2006) conducted a study of comparison of questions on mathematics textbooks in the US and China at the middle-class level. The study examined whether the questions were routine or non-routine, open or closed, using context or without context as well as traditional or non-traditional. The results show that routine, closed and traditional problems with no relevance to real-world situations dominate in the mathematics textbooks of the two countries. However, other results from the study show that 'more problems using context are found in US mathematics textbooks.

Other research related to textbooks in the US and China was also carried out by $\mathrm{Li}(\mathrm{Li}, 2000)$. Li compared the addition and subtraction of integer exercises in several American and Chinese math books in grade 7. In this study, a three-dimensional (3D) framework was used. The framework answers the types of mathematical questions (single or multiple calculation procedures) needed, contextual features (pure mathematical context or context of illustrative stories), and performance requirements (types of responses and cognitive needs). This study shows that both textbooks have problems with simple calculation procedures and pure mathematical contexts (not stories or illustrations). The difference is obtained in problem performance requirements: 
results show that in US textbooks more variation in problem requirements (e.g. explanations or solutions needed, conceptual understanding is needed).

Glasnovic Gracin (2018) uses the 5D framework in assessing practice questions and sample problems in mathematics textbooks in Croatia. The framework answers related questions about 1) What material do students need to know? 2) What activity (mathematically) needs to be done to solve the problem? 3) What is the complexity of knowledge and activities that need to be done to solve the problem? 4) What kind of answers are expected from the problem? 5) What is the context used in the problem? Based on this research, it was found that there was no balance of the questions presented in the mathematics textbook. The type of questions are closed, very algorithmic, and require low-level cognitive abilities that are found in the mathematics textbook under study. Meanwhile, questions with an open type, authentic context and require a high level of cognitive ability were not found in the mathematics textbook under study.

In this study, the framework is a modification of the framework developed by Glasnovic Gracin (2018) and Li (2000). The framework consists of six dimensions namely: mathematical activities (mathematical activities), the level of complexity of the problem (complexity level), the type of answer (answer form), contextual features (contextual features), the type of response (response type) and the type of mathematical questions (mathematical feature).

The dimension of mathematical activities consists of the ability of students to represent or model; count or use various count operations; interpret, and provide arguments or logical reasons. Whereas the dimension of the complexity level consists of the direct application of basic knowledge or skills (reproduction); establishing or making connections (connections); applying reflective knowledge (reflection). Then the type of answer (answer form) is closed, open and has multiple choices. Open answers are questions with many alternative answers (more than one), while closed answers are questions with only one correct answer. The contextual situation (contextual features) is a dimension that looks at the relationship between questions and the real-world context. This dimension consists of questions without context, realistic or fictional contexts and realworld contexts. The four dimensions above are modifications of the framework developed by Gracin (Glasnovic Gracin, 2018).

The dimension which is a modification of the framework developed by $\mathrm{Li}(\mathrm{Li}, 2000)$ is the response type and the type of mathematical features. The response type is the type of answer made by students to answer the problem, consisting of only answers (no reason), only reasons and answers using explanations. Then the mathematical features, on this dimension will be analyzed the relationship between the number of procedures used with the given problem. In this dimension, it will be seen: a single procedure and a layered procedure for solving a given problem. The purpose of this study is to analyze the types of problem in mathematics textbook that used in Indonesia between 2000 and 2017.

\section{METHOD}

This research is descriptive analysis research. The subjects in this study were questions on the material of the onevariable linear equation contained in junior high school mathematics textbooks from 2000 to 2017. The data collection method in this study was the collection of questions, both sample questions and practice questions from the mathematics textbook used in Indonesia from 2000 to 
2017. Mathematical questions in textbook are usually written as: "Example Questions" and "Practice Questions". The data are 473 questions presented from six mathematics textbook, consist of: two mathematics textbooks from CompetencyBased Curriculum, two mathematics textbooks from KTSP Curriculum and two mathematics textbooks from Curriculum 2013 (revision).

The framework in this study is a modification of the framework that developed by Glasnovic Gracin (2018) and Li (2000), consist of six dimension namely mathematical activities, complexity levels, answer forms, contextual features, response types and mathematical features for analyzing problems in mathematics textbooks in Indonesia. With this framework, the researcher will classify and convert the questions in the mathematics textbook into coding system.

Tabel 1. Dimension and Sub-dimension

\begin{tabular}{ll}
\hline \multicolumn{1}{c}{ Dimension } & \multicolumn{1}{c}{ Sub-dimension } \\
Mathematical Activity (A) & Representing or modelling (A1) \\
& Count or use various count operations (A2) \\
& Interpretation (A3) \\
& Give an argument or logical reason (A4) \\
& Application of direct knowledge or basic skills (B1) \\
Problem complexity (B) & Making connections (B2) \\
& Apply reflective knowledge (B3) \\
& Closed Answer (C1) \\
Answer type (C) & Open Answer (C2) \\
& Multiple Choice Answers (C3) \\
& Questions without context (D1) \\
Contextual situation (D) & Problem with the context of fiction (D2) \\
& Questions with real-world contexts (D3) \\
Response type (E) & Answers only (no reason) (E1) \\
& Reason only (E2) \\
& Answer using reason (E3) \\
Mathematical Questions (F) & Single Procedure (F1) \\
& Layered Procedure (F2) \\
\hline
\end{tabular}

Then each question will be classified according to existing dimensions and subdimensions, then the problem will be coded. So that the accuracy of the code is good, the researcher will carry out an intra-reliability process between two researchers and a mathematician (after this referred to as an expert). In this activity, researchers will take a sample of 100 questions, then researchers and experts will do the coding. The activity produced a value of 0.95 . This value, when compared with the value of intra-class correlation coefficient (ICC), is said to have "excellent" reliability because it is in the range of 0.75 to 1 .
Table 2. ICC Values (Cicchetti, 1994)

\begin{tabular}{cc}
\hline Value & Reliability \\
\hline$<0,04$ & Not Good \\
$0,04-0,59$ & Enough \\
$0,60-0,74$ & Good \\
$0,75-1$ & Excellent \\
\hline
\end{tabular}

\section{RESULTS AND DISCUSSION}

The results of the study indicate that in general there is no balance of types of questions in Mathematics textbooks in Indonesia for the Linear Equation of One Variable from Competency-Based Curriculum to Curriculum 13 (K13). Based on the dimensions of mathematical activity (dimension $\mathrm{A}$ ), questions on textbooks for all curricula are mostly still 
in the form of a type that counts or uses various count operations (A3). Whereas in the dimension of problem complexity (B), questions in the textbooks for all curriculums are still mostly in the form of questions of Direct type application of basic knowledge or skills (B1). In the dimension of the type of answer (C), all textbooks in the curriculum are very dominant, displaying questions with closed answers (C1) even above $75 \%$ of the questions. In the contextual situation dimension (D), there are still more types of questions without context (D1) in
Mathematics textbooks in Indonesia than those with fictional or real-world contexts. Whereas in the dimensions of the type of response (E), the dominance of the questions is only in the form of substantial answers compared to the types of questions with answers that require a reason. In the last dimension, the mathematical process $(F)$, the type of questions with a single procedure (F1) is very dominant compared to the questions of the layered procedure type (F2).

Table 3. Research Result

\begin{tabular}{lrrr}
\hline \multicolumn{1}{c}{ Sub-Dimensions and Codes } & \multicolumn{2}{c}{ Percentage } \\
Representing or modeling (A1) & \multicolumn{1}{c}{ KBK } & \multicolumn{1}{c}{ KTSP } & \multicolumn{1}{c}{ K13 } \\
Count or use various count operations (A2) & $43,64 \%$ & $14,17 \%$ & $11,36 \%$ \\
Interpretation (A3) & $56,36 \%$ & $85,83 \%$ & $72,73 \%$ \\
Give an argument or logical reason (A4) & $0,00 \%$ & $0,00 \%$ & $5,68 \%$ \\
Application of direct knowledge or basic skills (B1) & $0,00 \%$ & $0,00 \%$ & $10,23 \%$ \\
Making connections (B2) & $56,36 \%$ & $85,00 \%$ & $73,86 \%$ \\
Apply reflective knowledge (B3) & $43,64 \%$ & $15,00 \%$ & $20,45 \%$ \\
Closed Answer (C1) & $0,00 \%$ & $0,00 \%$ & $5,68 \%$ \\
Open Answer (C2) & $77,27 \%$ & $100,00 \%$ & $97,73 \%$ \\
Multiple Choice Answers (C3) & $0,00 \%$ & $0,00 \%$ & $1,14 \%$ \\
Questions without context (D1) & $22,73 \%$ & $0,00 \%$ & $1,14 \%$ \\
Problem with the context of fiction (D2) & $57,27 \%$ & $89,17 \%$ & $67,05 \%$ \\
Questions with real-world contexts (D3) & $12,73 \%$ & $4,17 \%$ & $27,27 \%$ \\
Answers only (no reason) (E1) & $30,00 \%$ & $6,67 \%$ & $5,68 \%$ \\
Reason only (E2) & $87,27 \%$ & $100,00 \%$ & $89,77 \%$ \\
Answer using reason (E3) & $0,00 \%$ & $0,00 \%$ & $0,00 \%$ \\
Single Procedure (F1) & $12,73 \%$ & $0,00 \%$ & $10,23 \%$ \\
Layered Procedure (F2) & $47,27 \%$ & $97,50 \%$ & $81,82 \%$ \\
\hline
\end{tabular}

Based on the research, it was found that textbook K13, had more variations than textbooks in the previous curriculum (KTSP and KBK). In the dimension of mathematical activities (dimension $\mathrm{A}$ ), questions in K13 textbooks related to the Intimacy (A3) sub-dimension and the subdimension of Giving Arguments or logical reasons (A4) have a higher percentage of $5.68 \%$ and $10.23 \%$ compared to the questions in the textbook in the previous curriculum, which have absolutely no problems with the A3 and A4 subdimensions. Whereas on the other hand, questions in Curriculum 13 textbooks related to the sub-dimension Calculating or using arithmetic operations (A2) have a smaller percentage than the questions in the KTSP textbooks. The exciting thing is on the sub-dimension of Representing or modelling (A1) KBK textbooks has a higher percentage than textbooks on other curricula, including K13.

In the Problem Complexity dimension (dimension B), questions in mathematics textbooks in all curricula are dominated by questions with the type of direct application of basic knowledge or 
skills (B1) with a percentage reaching more than $70 \%$. Whereas the types of the complexity of questions that Establish or make connections (B2) and Apply reflective knowledge (B3) have a much lower percentage of textbooks in each curriculum.

While in the dimensions of the type of answers (dimension $\mathrm{C}$ ), the types of questions in the textbooks in each curriculum are highly dominated by the types of questions with closed answers (C1) with a percentage of more than $75 \%$. Types of questions with open answers (C2) are rarely displayed in mathematics textbooks in Indonesia.

In the contextual situation dimension (dimension D), the types of questions without context (D1) are still more than $55 \%$ of the questions in Indonesian mathematics textbooks for the material of linear equations of one variable. Problems with the context of fiction (D2) began to be widely displayed in K13 curriculum books, reaching 27.2\%. Next, the problem with real context (D3) still gets a limited portion of Indonesian mathematics textbooks for the material of one-variable linear equations.

In the response type dimension (dimension E), the type of questions that are only answers or no reason (E1) still dominates the questions in Indonesian mathematics textbooks for linear onevariable equations, reaching more than $88 \%$ of the existing problems. Whereas questions that require answers with the reason (E3) only get a minimal portion of Indonesian mathematics textbooks. Even problems that only need a reason (E2) are not displayed at all in all mathematics textbooks.

In the mathematical process dimension (dimension $F$ ), the type of questions with a single process (F1) has a higher percentage than the type of questions with a layered process (F2), except for textbooks in the CBC. Except for the KBK textbooks, the type of questions with a single process is more than $80 \%$ of the questions in the Mathematics textbook for the material of one-variable linear equations. Whereas questions with multilayered process types are displayed with a minimal amount.

It can be seen that in the dimension of mathematical activity, the dominant type of problem so far is the one that counts or uses various count operations while problems with the representing, interpreting and providing logical arguments do not get the right portion. In addition to the dimensions of problem complexity, the types of questions that apply basic knowledge or skills directly are very dominant in mathematics textbooks so far. The types of questions that can establish connections or apply reflective knowledge are relatively limited. In the contextual situation dimension, there are very few types of questions in the fictional or real context. The results of the above study may be a reason that explains Indonesia has a bad result at PISA; this is in line with (Glasnovic Gracin, 2018). The focus of PISA is mathematical literacy ability, which is defined as the ability of students to formulate, apply and interpret mathematics in various contexts (OECD, 2016).

One thing to note is that the types of questions in the Curriculum 13 textbooks begin to be more diverse than the mathematics textbooks for linear variable one-variable equations in the previous curriculum. On the dimensions of mathematical activity (A) questions with the Interpreting and Giving arguments or logical reasons are displayed more than textbooks in the previous curriculum. The same thing can also be seen in the dimension of problem complexity (B), the types of questions that build connections and reflective capabilities are more numerous than the previous curriculum. On the other hand in the contextual situation dimension (D), there are more 
types of questions with fictional or real contexts than the previous curriculum. Based on Wijaya, A., Heuvel-Panhuizen, M., \& Doorman, M. (Wijaya et al., 2015), the type of questions with context forces students to choose, add or even ignore information. In such a way that the selected information is sufficient to solve the problem given. Even so, the range of questions in the Curriculum 13 textbooks has begun to be overwhelming. The number of questions is still minimal. Even in the dimension of the type of answer (C) the type of questions with open answers is only $1.14 \%$ (or only 1 of the 100 existing questions). Based on Kurniawan $\mathrm{H}$, et al. (Kurniawan et al., 2017) questions with open answer types provide opportunities for students to improve their mathematical abilities, including reasoning abilities, communication skills and problem-solving skills.

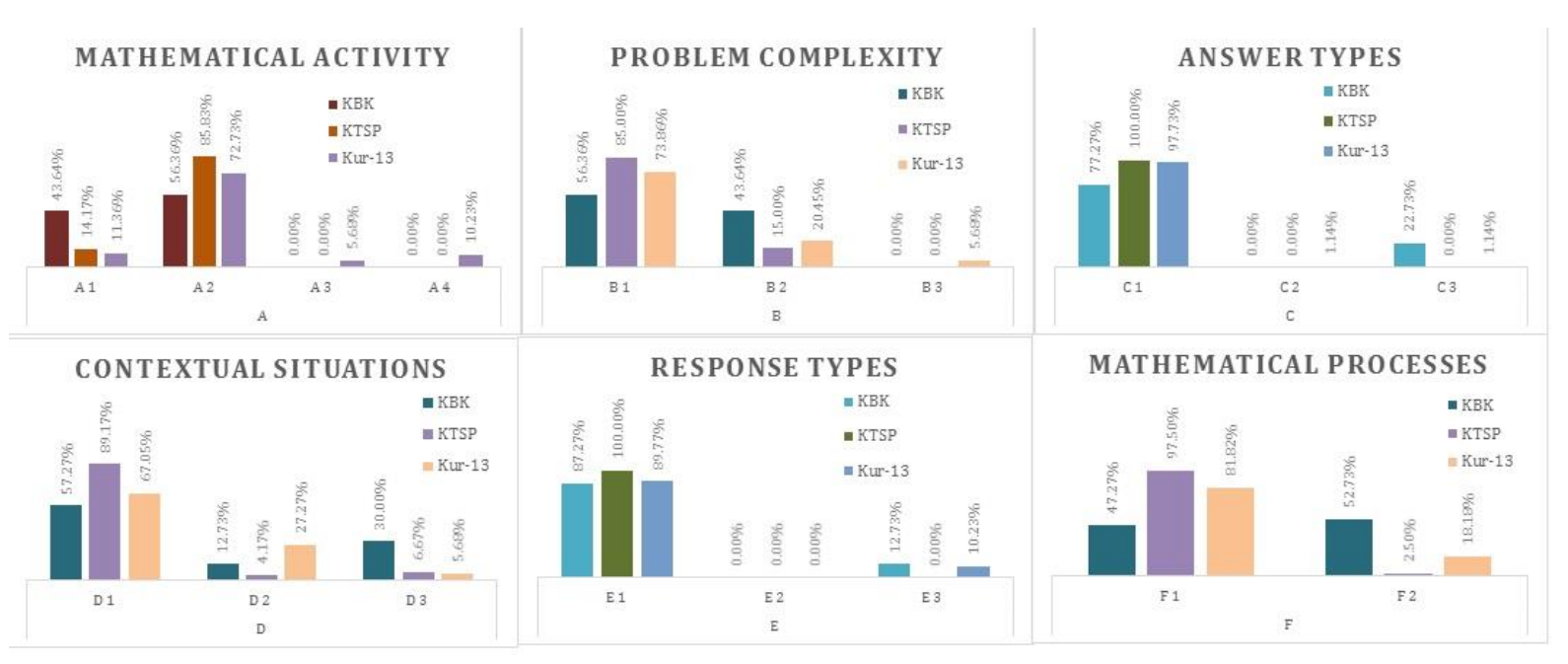

Picture 1. Diagram and Percentage Research Result

\section{CONCLUSIONS AND SUGGESTIONS}

Questions on mathematics textbooks for one-variable linear equations material do not have diverse types, there are still many types of questions in textbooks in the form of questions that calculate or use a variety of arithmetic operations, apply the knowledge directly or basic skills and without context in everyday life. Also, the existing questions are questions with closed answers, questions that only require answers without a reason and problems with a single procedure. However, the types of questions in Curriculum 13 textbooks begin to be more diverse than mathematics textbooks for the one-variable linear equation material in the previous curriculum, even though the numbers are still minimal.
The framework in this study can not only serve as a reference for further research, but can also be used by mathematics textbook writers to create more diverse types of questions. Further research on this issue is suggested in order to conduct comparative research between the issue of mathematics textbooks in Indonesia and other countries, in particular those with a better PISA result. Another research suggested, highlighting the gender biases and stereotyping that occur in the Indonesian mathematics textbook question.

\section{REFERENCES}

Brändström, A. (2005). Differentiated tasks in mathematics textbooks an analysis of the levels of difficulty [Luleå University of Technology]. In 
Dissertation. http://www.divaportal.org/smash/record.jsf?pid=div a2\%3A991116\&dswid=-4967

Cicchetti, D. V. (1994). Guidelines, criteria, and rules of thumb for evaluating normed and standardized assessment instruments in psychology. Psychological Assessment, 6(4), 284-290. https://doi.org/10.1037/10403590.6.4.284

Glasnovic Gracin, D. (2018). Requirements in mathematics textbooks: a fivedimensional analysis of textbook exercises and examples. International Journal of Mathematical Education in Science and Technology, 49(7), 10031024.

https://doi.org/10.1080/0020739X. 2018.1431849

Huntley, M. A., \& Terrell, M. S. (2014). Onestep and multi-step linear equations: a content analysis of five textbook series. ZDM - Mathematics Education, 46(5), 751-766. https://doi.org/10.1007/s11858014-0627-6

Kurniawan, H., Putri, R. I. I., \& Hartono, Y. (2017). Developing open-ended questions for surface area and volume of beam. Journal on Mathematics Education, 9(1), 157168.

https://doi.org/10.22342/jme.9.1.46 40.157-168

Li, Y. (2000). A Comparison of Problems That Follow Selected Content Presentations in American and Chinese Mathematics Textbooks. Journal for Research in Mathematics Education, 31(2), 234. https://doi.org/10.2307/749754

Love, E., \& Pimm, D. (1996). 'This is so': a text on texts. In C. L. Alan J. Bishop, Ken Clements, Christine Keitel, Jeremy Kilpatrick (Ed.), International Handbook of Mathematics Education
(Volume 4, pp. 411-434). Springer Netherlands.

https://doi.org/10.1007/978-94009-1465-0_12

Niss, M. (1993). Assessment in Mathematics Education and Its Effects: An Introduction. In M. Niss (Ed.), Investigations into Assessment in Mathematics Education (Volume 2, Vol. 2, Issue 9, pp. 1-30). Springer Netherlands.

https://doi.org/10.1007/978-94017-1974-2_1

OECD. (2016). Overview: Excellence and Equity in Education: Vol. I (pp. 33-47). https://doi.org/10.1787/97892642 66490-5-en

Özgeldi, M., \& Esen, Y. (2010). Analysis of mathematical tasks in Turkish elementary school mathematics textbooks. Procedia - Social and Behavioral Sciences, 2(2), 2277-2281. https://doi.org/10.1016/j.sbspro.20 10.03.322

Watson, A., \& Geest, E. De. (2005). Principled Teaching for Deep Progress: Improving Mathematical Learning Beyond Methods and Materials. Educational Studies in Mathematics, 58(2), 209-234. https://doi.org/10.1007/s10649005-2756-x

Wijaya, A., van den Heuvel-Panhuizen, M., \& Doorman, M. (2015). Opportunityto-learn context-based tasks provided by mathematics textbooks. Educational Studies in Mathematics, 89(1), 41-65. https://doi.org/10.1007/s10649015-9595-1

Zhu, Y., \& Fan, L. (2006). Focus on the Representation of Problem Types in Intended Curriculum: A Comparison of Selected Mathematics Textbooks from Mainland China and the United States. International Journal of Science and Mathematics Education, 
Desimal, 3 (2), 2020 - 97

Aji Raditya, Ratu Sarah Fauziah Iskandar, Suwarno

$4(4)$,

609-626.

https://doi.org/10.1007/s10763-

006-9036-9 
Desimal, 3 (2), 2020 - 98

Aji Raditya, Ratu Sarah Fauziah Iskandar, Suwarno 